\title{
Dealing with students' diverse skills in maths and stats
}

Karen Jackson, University of Bradford

Edited by Ross Guest, Griffith University, Australia

Published December 2012

Dealing with students' diverse skills in maths and stats .............................................. 1

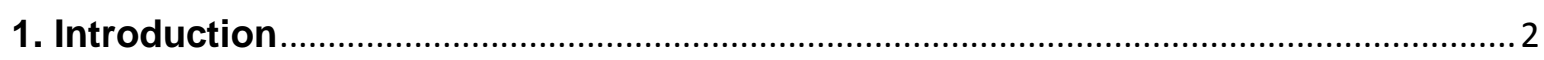

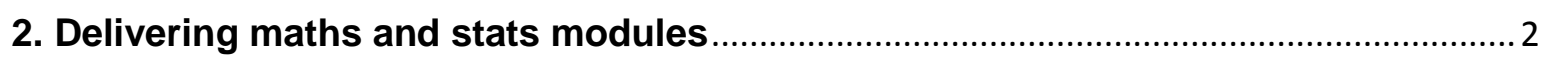

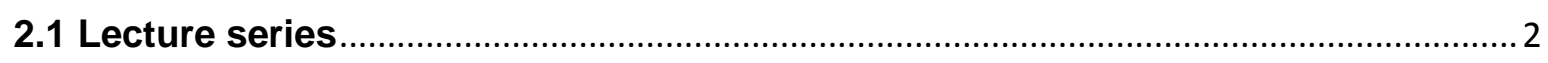

2.2 Assigning students to seminar/tutorial groups, and organising groups in seminars/tutorials ........................................................................................................

2.3 Making maths and stats engaging and interesting .............................................. 8

2.4 Engaging students with strong maths and stats skills ........................................12

2.5 Support staff and sessions to complement core delivery .....................................13

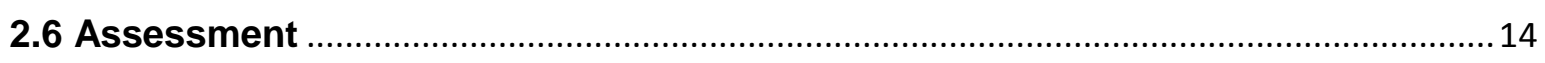

3. Delivering economics modules relying on maths and stats skills...........................16

3.1 The balance of maths and stats content in economics lectures .......................... 16

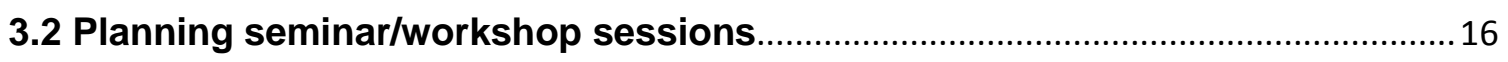

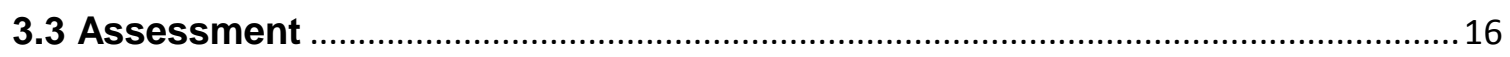

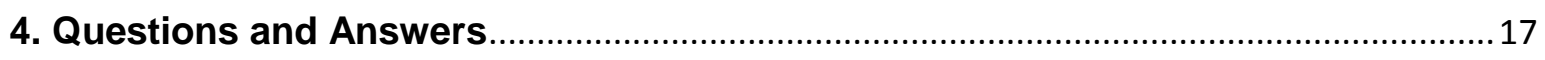

4.1 What can I do if I am teaching a first year maths module with a high failure

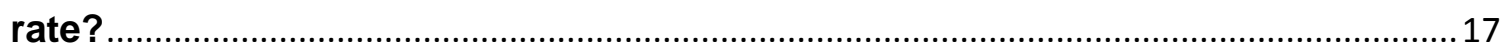

4.2 Students are passing the $1^{\text {st }}$ year maths module but the staff teaching $2^{\text {nd }}$ year microeconomics and macroeconomics are concerned that students are not familiar with key maths/stats concepts. What should I do? ....................................... 18

4.3 I am teaching a maths/stats module and running lectures and seminars/workshops but attendance is very low. What should I do?

4.4 I am teaching a maths/stats module and the weak students are no longer attending the sessions. What should I do? ............................................................... 19

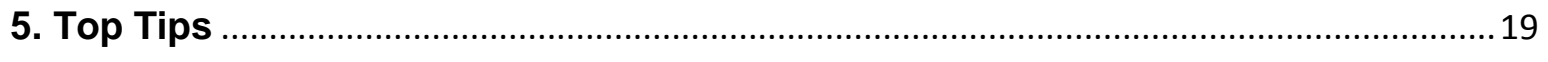

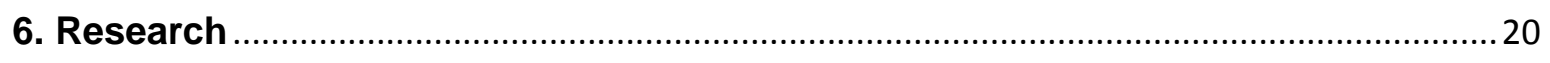

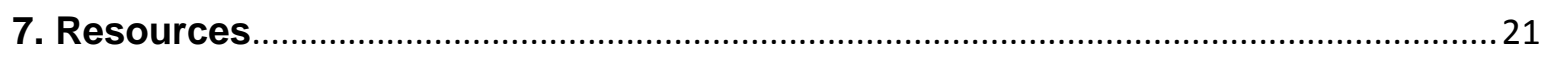

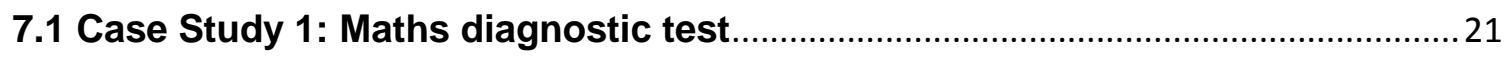

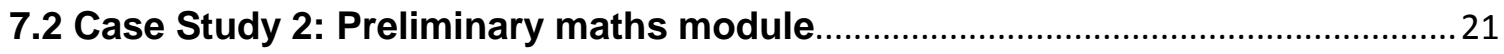




\section{Introduction}

The starting point for this chapter is the 'maths problem' in United Kingdom Higher Education (UK HE). This provides a challenging environment for the delivery of both maths and stats teaching in many subjects, particularly economics that is the focus here. Many assume that the 'problem' is only in teaching students who illustrate very limited maths ability or confidence. In fact, the diversity of maths ability is a major issue. This is increasingly the case as UK HE attracts a high number of students from the European Union (EU) as well as outside the EU, and thus an increasing number of students from diverse educational backgrounds. This general upward trend in students coming from outside the UK is reflected in the background of students choosing to study economics.

This chapter will draw a distinction between maths and stats modules, compared to other economics modules that rely on understanding of maths and stats. Its aim is to provide guidance together with a selection of 'hints and tips' to assist practitioners, rather than outlining a review of the education literature. The sections have been kept moderate in length, and an effort has been made to allow the reader to be able meaningfully read discrete sections so that someone can dip in-and-out of the chapter.

Towards the end of the chapter there is a question and answer section that aims to provide step-by-step advice to overcome key problems when teaching maths and stats.

\section{Delivering maths and stats modules}

\subsection{Lecture series}

The traditional approach to teaching maths and stats modules is to deliver a lecture or more per week. Despite emerging discussions of a problem-based learning approach few lecturers have fundamentally changed their teaching style. Nevertheless, maths and stats modules are ideal for trialling such an approach. Typically maths and stats students in schools and colleges learn by a relatively light touch lecture style teaching, involving short demonstrations and a high proportion of practical work undertaken by the students. However there is reluctance to move to this format in Higher Education. Partly this seems to be due to a difficulty in identifying how this approach could be formulated in a university context. It is also undoubtedly more difficult to plan for such an approach given the resource constraints that ever larger cohorts entail.

Despite these challenges, it is worth considering the problem-based approach. A basic overview of the structure of the approach is: 
1. Problem

2. First meeting

3. Research

4. Feedback meeting

5. Response

The problem-based style of learning can be used in a variety of different formats. One set-up would be for all the teaching sessions to be designed around setting groups of students the task of working through problem sets. The role of the teaching staff in the classroom is then to offer advice as needed. This could be followed by the presentation of the group findings. In this set-up there would be no lectures, essentially meaning the sessions are workshops/clinics. A drawback of this approach is that students may not recognise the sessions as part of a 'proper' module and therefore be less willing to fully engage. If this approach were used successfully there would be a need for very clear guidelines on expectations and learning outcomes.

Another issue that is arises with respect to the problem-based learning approach is that students may become reliant on the group, meaning that they may struggle to carry out problem solving in an independent context. Therefore if you undertake the problem-based learning approach it may be sensible to also consider incorporating individual assessment into your maths/stats module, both formative and summative.

Lectures can provide a useful function, even in a practical subject that lends itself to learning-by-doing. Lectures can act as signposts so that students become aware of what should be their current level of learning and the expectations for future learning. Lectures also provide an effective mechanism for delivering material to a large number of students, avoiding the repetition that can prove very draining for staff teaching on a one-to-one basis. However, the effectiveness of a large group lecture depends on a number of factors. Teaching staff often find lecturing maths and stats in modules to be problematic due to the diverse ability of the students. It takes a very well planned and skilled member of teaching staff of deliver a lecture that students, across the ability spectrum, successfully learn from. Alternatively you may find that you have a group of students with very weak skills and in this context lecturing may not be a useful teaching medium. In contrast to the lecture, one-to-one sessions allow teaching staff to build up an understanding of the range of experience, ability and confidence of different learners and the unique barriers they may face.

Supplementing student-focused workshops with occasional lectures (not on a weekly basis) may be an appealing alternative. The lecture allows for sign-posting key techniques whilst seminars/tutorials with one-to-one support can be used to focus on the range of challenges arising from a diverse student body. The merits of 
these different approaches, broadly outlined in this section, centrally depends on the composition of your group of learners. ${ }^{[1]}$

The diversity of maths ability of a cohort will vary depending on entry requirements. For example, it is likely to be much larger in those programmes that require only a minimum of GCSE-level maths compared with those that require Alevel maths and, hence where students have more recent and similar experience. The level of overseas student recruitment adds another dimension to this. Where diversity is an issue, you may also wish to consider offering a preliminary module in order to narrow the gap between your diverse range of learners, with attendance dependent on a screening test on entry. If a preliminary module is in place, this may allow a more 'traditional' approach to be used in subsequent modules, including a weekly lecture series.

Whatever the degree of variation in entry qualifications, in order to effectively teach a range of learners you must be able to identify the skills of different students. Therefore in the next section we will consider the merits of screening and streaming students.

${ }^{111}$ The decision can be influenced by financial and physical constraints. A weekly lecture series will tend to be cheaper, in terms of staff costs, than a set of smaller problem based classes. Teaching space is often organised to facilitate a large group lecture, tiered rows in a large room, and this is not the kind of facility conductive to problem-based learning.

\subsection{Assigning students to seminar/tutorial groups, and organising groups in seminars/tutorials}

There are wide-ranging views on whether students should be streamed according to their maths/stats ability when allocating students to teaching groups.

Fundamentally the decision depends on the student body you are teaching. Your entry requirements and past experience may suggest that the students taking your maths/stats module are of a roughly similar ability. In this case it may be more appropriate to consider allocating students on the basis of other concerns around integration and team-building. In this case weaker students can be offered access to additional support outside of seminars and workshop activities.

However, typically, a key issue regarding teaching maths/stats modules is how to deal with a diverse student body in terms of maths/stats ability. In such circumstances, if groups are allocated on a basis other than ability some students may be reluctant to ask 'simple' questions in front of peers who they perceive to be more able. This can lead to the less confident students not making sufficient progress through the syllabus. Conversely, in such mixed sessions other more 
confident and able students may find the sessions 'boring' and therefore disengage, with similarly depressing effects on performance.

When streaming is considered there are always concerns among staff that some students will perceive that they have been labelled as weak because they are in the 'bottom' group. There is no denying that this may be a real issue. However, there are ways to mitigate the potential downsides, as discussed below. Essentially the problem can be met head-on by explaining the allocation of students to seminars in an open and frank discussion with the students themselves and by building an understanding of the fact that we are all good at different things. In addition it is important to remind students that the streaming may be incorrect and that they should request to change groups if they find their allocated group moving too 'fast' or 'slowly'. By following these steps you can create an environment in which students themselves participate in deciding the best learning environment and as a result will not feel 'stuck' in a particular group.

There will also need to be an emphasis that all groups will cover the core material. Together, the emphasis that students are not 'stuck' in a group and that all groups will be taught the same core material should counter any negative connotations that students may have of streaming from school where these features are absent and different classes may indeed cover a varying syllabus. This approach finds support in the educational literature. Dancer and Fiebig (2004) note the usefulness of streaming to allow different styles of teaching to cater for varying maths ability, with streaming allowing staff to target at risk (of failure) groups. Similarly Alauddin and Butler (2004) note the benefit from streaming students and providing differentiated offerings, although the authors recognise that teaching to the median student in a lecture room is cheaper and that there are resource-induced tensions in the modern university.

If you decide to stream your students into groups based on a screening test you may also wish to consider sessions of different lengths. This is because although you may target a group who require additional foundational support using the test, there is still likely to be considerable diversity within this group (the greater the higher is the threshold pass mark in the screening test used for allocations). For example, you may want to allocate the more maths/stats able students to one-hour sessions and weaker students to two-hour sessions. This can help reinforce the fact that the same core material will be discussed in all sessions, albeit at different speeds across the groups. An alternative is to provide additional support sessions for students who wish to access this support. However those students who need this support - and recognise the fact - will often have other competing pressures on their time and therefore be less likely to make the time unless it is part of their scheduled activities. Accordingly, by formalising the additional support in different length sessions you can have more confidence that you will reach the students who may benefit most from it. 
If streaming your students seems appropriate then the first practical consideration is what results to base this on. Assuming that the data is available then maths entry grades could be used for this purpose. However for some students these grades will have been obtained two or more years before starting university or be based on various overseas qualifications. Therefore it may be sensible to consider screening test prior to the start of the module to establish a current baseline of knowledge.

The next consideration is designing your test. A multiple choice test will allow for quick marking, as turn-around time is likely to be an issue, and you may consider on-line testing to avoiding marking altogether. It is perfectly acceptable to use a multiple-choice test in this setting as long as it is well designed. There is a range of guidance available to assist you, including that available via the Economics Network website. The main considerations are that enough answers are available as options and that these options are sensible in terms of the rational routes that students may have taken to solve the question.

It is worth bearing in mind that while on-line testing has obvious appeal there are a number of issues to be borne in mind. You will need to ensure that you can find a large enough computer room to carry out the testing. The other issue is that it takes time to become familiar with the on-line testing software available at your institution and you will need to make sure technical support is available on the day of the test. The reality is that you will also have some students arriving late and therefore a mixed economy of on-line and paper-based testing will nearly always be required. You will also want to make sure you have a paper-based back-up in case the system 'crashes' or some other unforeseen event occurs.

It is important to review your processes and to continue to tailor your approach to the needs of your students in the light of experience. In particular, the screening test threshold mark for allocating students to a preliminary support module or to longer workshop sessions will require review and reflection. As part of this process it is helpful to check that the test has appropriately streamed the students at the end of the maths/stats module. Checking the correlation between the screening results and final grades in the module concerned can be useful guide. Ideally streaming will have delivered added value bringing all students up to a similar level. However, in reality maths/stats learning takes more time a typical module allows to bring students to a similar level and so it is to be expected that there will remain some degree of positive correlation between screening results and end of module results.

If you decide to carry out streaming you may still involve students in group work within the streamed seminar classes. There needs to be thought given to determining the make-up of these within-class groups. Learners have different styles: activist, reflector, theorist and pragmatist. There is some evidence to suggest that it is useful to try and select students with similar learning styles into a group (Dunn et. al. 1995). Table 1 explains these types of learners. You may wish 
to set an exercise, or a learning style questionnaire (see, for example, Entwistle, 1981; Honey and Mumford, 1995), and then ask the students themselves to identify their learning style in order to help group formation.

Table 1 Seminar activities appropriate to each type of learner (according to 'experiential learning')

\begin{tabular}{|c|c|}
\hline \multicolumn{2}{|l|}{ Activist style } \\
\hline $\begin{array}{l}\text { Learns best from activities } \\
\text { where: } \\
\text { - } \\
\text { there are new } \\
\text { experiences/problems, } \\
\text { etc.; } \\
\text { - } \\
\text { they can become } \\
\text { engrossed in short } \\
\text { tasks, games, } \\
\text { competitive teamwork } \\
\text { tasks, etc.; } \\
\text { there is } \\
\text { excitement/drama/crisis } \\
\text { and things chop and } \\
\text { change with a range of } \\
\text { diverse activities to } \\
\text { tackle; } \\
\text { there is chance of } \\
\text { limelight, e.g. leading } \\
\text { discussions, giving } \\
\text { presentations; } \\
\text { they are involved with } \\
\text { other people, e.g. } \\
\text { bouncing ideas off } \\
\text { them, solving problems } \\
\text { as part of a team. }\end{array}$ & $\begin{array}{l}\text { Learns least from activities where: } \\
\text { - learning involves a passive role, e.g. listening to } \\
\text { lectures, reading, explanations; } \\
\text { - } \quad \text { they are not directly involved; } \\
\text { - they are required to assimilate, analyse and } \\
\text { interpret lots of data; } \\
\text { - they are required to engage in solitary work, i.e. } \\
\text { reading, writing, thinking on their own; } \\
\text { they are asked to repeat the same activity over and } \\
\text { over again. }\end{array}$ \\
\hline \multicolumn{2}{|l|}{ Reflector style } \\
\hline $\begin{array}{l}\text { Learns best from activities } \\
\text { where: } \\
\text { - they are encouraged to } \\
\text { watch/think/chew over } \\
\text { activities; } \\
\text { they are able to } \\
\text { listen/observe a group; } \\
\text { they can reach a } \\
\text { decision in their own } \\
\text { time without pressure } \\
\text { and tight deadlines. }\end{array}$ & $\begin{array}{l}\text { Learns least from activities where: } \\
\text { - they are forced into the limelight; } \\
\text { - they are worried by time pressures or rushed from } \\
\text { one activity to another; } \\
\text { - they are pitched into doing something without } \\
\text { warning. }\end{array}$ \\
\hline
\end{tabular}




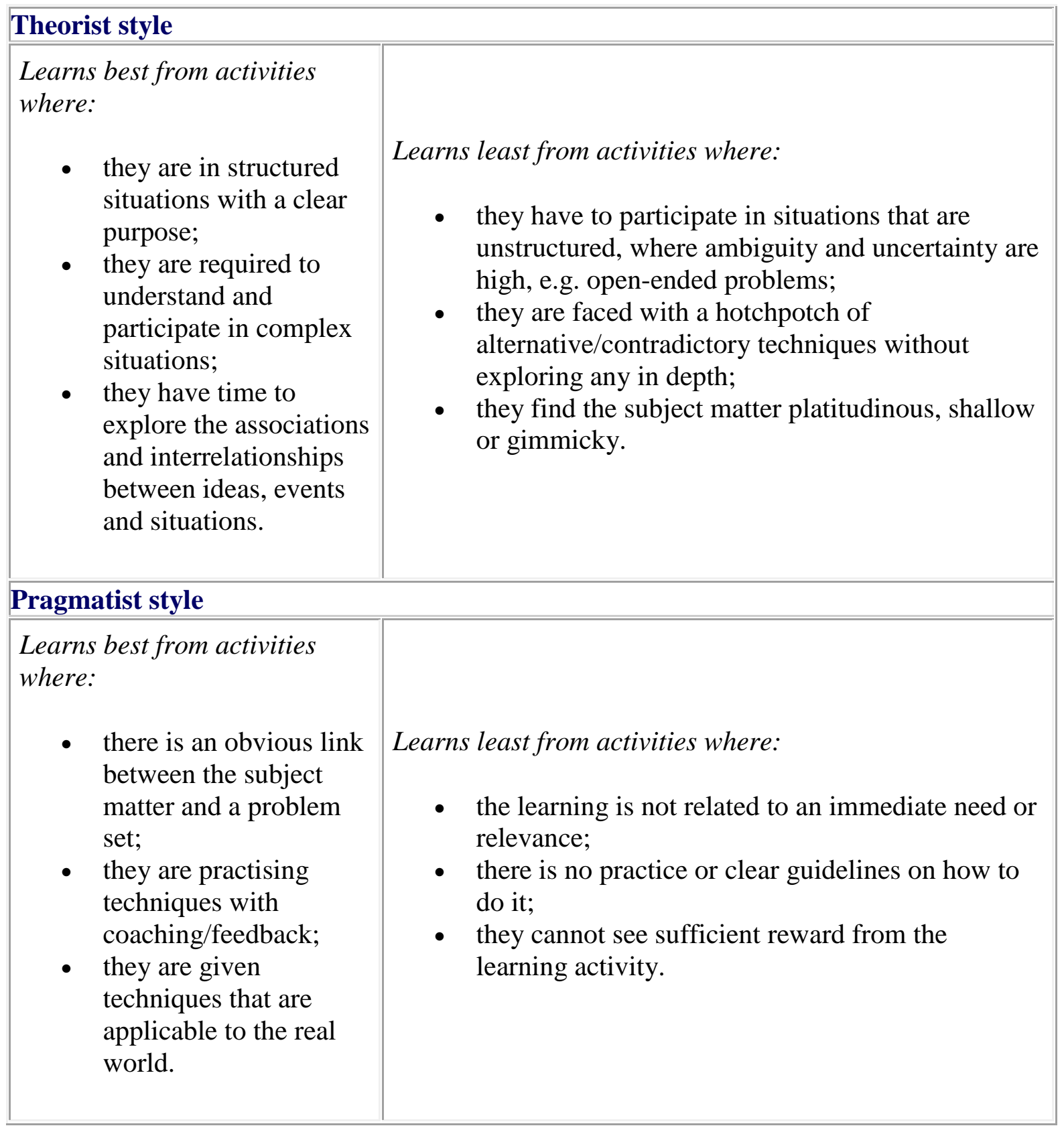

Source: Honey and Mumford (1995).

\subsection{Making maths and stats engaging and interesting}

Once the format of the teaching sessions and method of assigning students to various sessions has been decided the key issue of making maths interesting for students with diverse skills must be given some thought. One of the most obvious initial steps is to illustrate key maths and stats techniques using economic examples. This approach can help weaker students understand the concepts better as they are then able to identify the relevance of the maths techniques in terms of economic applications. In addition, stronger students may be stretched by 
attempting more advanced economics applications using their maths skills. However, this alone is often not sufficient unless the examples are familiar from the core economics modules students are studying concurrently. This can be more difficult than it appears in year one since students may have limited exposure to maths and stats within the core economics modules, making the linking more difficult, or there may be issues relating to the sequencing of the economic concepts and the relevant mathematical or statistical technique. Further, this may be further compounded by the need to cover maths and stats techniques in the first year that will be used in economics modules later in the degree programme.

Ideally module leaders from a range of maths, stats and core economics modules need to sit down together and agree on the linkages, common examples and sequencing where possible. Staff teaching core economics modules at stage one may be reluctant as they can take the view that they are being asked to spend time teaching maths and stats within their modules and that this should be placed elsewhere. To overcome this, the discussion should focus on how a linked up coherent approach can make the job of a core economics module leader easier.

Maths and stats teaching and learning usually requires a cycle of demonstrating and practicing a technique. The extent to which this cycle needs to be pre-empted or followed by an economics application requires thought. Some learners prefer to become very confident with a technique before considering applying it to an economics context. Other students need to understand why they are learning a technique before they can engage with the learning process. Evidence suggests that the more effective approach will depend on the educational/cultural background of your particular group of learners. Leung (2001) provides a discussion of the differences between East Asian and Western maths education. The author draws a distinction between the East Asian approach to content (i.e. basic knowledge and basic skills) and the Western focus on process (i.e. understanding how knowledge is arrived at). Therefore you should consider the diversity of skills and educational background amongst your students and adapt your approach accordingly.

In terms of delivery, the current dominant approach to lecturing in UK HE is to use Powerpoint slides. In the context of maths and stats teaching the use of Powerpoint can be useful in that it provides to students with an outline of the structure of the lecture and key points. Nevertheless, an over-reliance on Powerpoint is often unhelpful as weaker students need practice following detailed examples, which is difficult to illustrate on slides without making them very cluttered. Moreover, good students tend to lose interest unless they are stretched to solve difficult problems.

'Chalk and talk' is often criticised in the current education literature as a sign of the outdated teaching styles employed in economics. However this technique should not be completely disposed of as there is merit to it. Seeing a tutor solve a problem in real time is often re-assuring for students. Therefore a balance between 
demonstrating a technique with 'chalk and talk' while summarising the key points on a Powerpoint slide may be a sensible.

Even when the student body allows for a passive lecture experience it is unlikely to prove enjoyable for either lecturer or student. There are a number of possibilities as to how lectures can be made a more active learning experience for a range of learners. Below is a list of suggestions:

1. Go through a demonstrate-and-practice cycle in the lecture slot by asking students to solve another similar example to the one demonstrated. You can encourage stronger students to work with and encourage weaker students.

2. Ask students to complete a paper-based multiple-choice quiz at the end of the lecture. The key to ensuring engagement with this activity is to walk round the lecture room and provide feedback on interim answers. If you simply stand at the front of the lecture you may find a large number of students do not even attempt the questions. The simple act of walking up the aisle of a lecture can maintain concentration on the exercise for most students. You could ask students to mark their neighbour's answers and ask for a show of hands regarding number of correct answers on the paper marked by each student. This should provide information as to how well you are delivering to your range of learners.

3. You can use online software such as Quizdom to run quizzes during and at the end of the lectures. If suitable software can be downloaded onto student mobile phones this may ease the organisation of this kind of testing. Alternatively students could be provided with a personal handset at the start of the year by the department for a paid deposit. If this system can be made operational it provides a very effective mechanism to ensure active learning. The advantage of on-line testing in real time during the lecture is that students can actually see whether most students have obtained the correct answer. This provides a good opportunity for students to benchmark their understanding against other students. The lecturer can also recognise where there is a broad lack of understanding and attempt to address this in future sessions. In addition, a lecturer should be able to identify any gap in learning between students with different abilities as results are easily stored.

4. At the start of the lecture series create teams of students, with the number in each team determined by the size of the class. You need to give some thought to the rules for defining how these teams can be set-up. In other words, you do not want teams organised by maths ability so you may suggest that each team should be comprised of students from a particular number of countries of birth.

Alternatively, if most of your students are born in the UK you may suggest a composition according to GCSE or A-level results. You could agree on a prize for the winning team, or it may be best to keep it a surprise. Each week you could set a maths problem and note the team with the first right answer. To encourage attendance you could set a minimum number of students per team that must be 
present in each lecture otherwise the team will be disqualified. The difficulty of the questions set each week should depend on the length of time required for the lecture. This type of activity should develop mentoring within teams of students with diverse abilities.

5. You may consider showing short videos illustrating the economic application of a particular technique. A number of videos are available from the METAL project. This may provide weaker students with an understanding of the usefulness of maths techniques as well as stretching stronger students.

Turning to consider seminars and workshops the following possibilities are available:

1. The traditional approaches to seminars are either to ask students to present their answers on the board or to ask students to work through the questions individually with one-to-one support on hand. If the majority of students have attempted the questions in advance then going through the answers on the board may be a sensible approach. However weaker students may not know how to start the questions. To overcome this problem provide a quick example then ask them to try the problems individually with support. Weaker students often favour the individual work with support option. Whichever broad approach is used, and this may vary from session to session, adding in another dimension (ideas below) to part of the session may keep things interesting (ideas below).

2. It may be worth considering setting up groups and suggest that these are study groups that can meet outside the teaching sessions. You may wish to offer these groups access to a room to meet at another time in the week following the session. The composition of these groups is important and you need to have a classroom set-up to facilitate this type of session. This approach may work best with weaker ability students.

3. It may be appropriate to ask students at a later stage in their studies to come along to teaching or study sessions and act as mentors. This may be helpful with groups of weaker students who may struggle to attempt the questions without support. Mentors may be encouraged to engage with this activity as it positively reflects on their $\mathrm{CV}$. Alternatively you may wish to consider awarding credits as part of a mentoring module for this activity or provide some remuneration. However, if willing volunteers can be found without the promise of credits or remuneration they may be the most valuable assistants.

4. Another option worth exploring within a workshop setting is to encourage students who have finished the problems to 'teach' other students. You would need to explain that teaching ensures deeper learning. 
5. Question Time! At the end of a session you could split students into groups. Ask each group come up with a question and have a worked solution. This activity ensures that students are aware of the broad set of questions within a 'type' and thus the common approach to their solution. Ask the groups to solve each other's questions and then have an answer session to establish whether the correct answer has been arrived at. Alternatively have each group ask the next to solve a question until no group can answer a particular question and the winning group is the only one left. The tutor can get involved in this type of activity by being a group in their own right or helping a weaker group. This can work well as a wrap-up session as the stronger students are encouraged to stay until the end.

6. Provide students with some questions to practice a particular mathematical or statistical technique. Split the students into groups and ask the students to come up with a question applied to economics and present the solution. This could be presented on an overhead transparency or you may wish to encourage students to bring along a laptop to type up their answer before showing this via an overhead projector. This approach may allow a tutor to engage stronger students.

7. You can use online software such as Qwizdom to run quizzes at the middle or end of sessions. (See previous section regarding further considerations for using this type of system).

8. The reality of the focus on assessment is that students may engage with sessions only if they can clearly identify a link with the seminar/workshop material and the assessment for the module. Therefore you may wish to include past exam paper questions as part of the classroom work. Alternatively, encourage students to attend sessions by explaining the questions will be of a similar 'type' to that included in the module assessment. It is important to stress that the full range of learners will be formally assessed in the same way. This should encourage weaker students to put in more time to 'catch-up'.

9. Computer-based learning can complement traditional delivery and help embed concepts. See section 2.4 for a further discussion.

\subsection{Engaging students with strong maths and stats skills}

A key issue when delivering a maths and stats module of learners with diverse ability is how to keep those with a strong ability engaged, as there is a tendency to deliver to the lowest ability in the student body. A few practical examples of how to maintain the engagement of stronger students are outlined below:

1. There is a vast array of software that can be used to complement key delivery of maths and stats modules. This software ranges from maths and stats packages such 
as Matlab, Derive, Maple, SPSS, Eviews, Microfit, STATA. There is also a range of open source software and you could consider using Excel. You may also consider using e-learning support software that complements various textbooks. While this type of software may help to embed key concepts it can also prove a useful tool in setting extension work for stronger students. One method may be to use a computer lab with the added facility of a central area of tables and chairs. This set-up would allow students to carry out paper-based exercises and then start on the computer-based activities depending on the speed of progress. The advantage of this approach is that one-to-one help can be offered to those attempting paper-based exercises while stronger students work through computerbased activities independently.

2. The traditional approach to deal with more advanced students is to set an additional number of 'challenging' problems. However students may not engage with the more advanced question just because they have been asked to do so. As a result you may wish to consider a competitive element to solving the more advanced questions. You may consider offering a prize for the student who is the first to answer the most of these questions correctly over the teaching sessions.

3. You may consider designing your assessment so that the students that have engaged with more advanced problem solving in classes are able to have more confidence in attempting more difficult assessment questions.

4. You may find that a substantial number of students with strong maths and stats ability actually find it more difficult to apply the techniques to economic problems. Therefore, rather than asking the more able maths and stats students to attempt more advanced problems practicing the same generic maths and stats techniques you can set problems that involve students tackling problems using the techniques in the context of the material covered in the core economics modules.

5. If you have decided to stream your seminars/workshops for maths or stats you may have scope to arrange some presentations during the sessions for more advanced students. This may take the form of asking a group to produce a short (perhaps 5/10 minute) presentation summarising the key learning outcomes and for these to be delivered at the end of the session each week.

\subsection{Support staff and sessions to complement core delivery}

The support staff available depends on the structure of each institution. If you have a central support unit that includes maths advisors this is an ideal resource. However, central support can often remain de-linked from module delivery and as a result students may not recognise the role of these central staff in supporting their learning. If possible, within the organisational structures, you may wish to ask 
central support staff to attend maths and stats seminars/workshops. This will provide the session leader with extra resource as well as providing central support staff an understanding of the needs of your learners. It also helps students to identify these staff as central to their learning and teaching experience. If students feel that central support staff understand the material covered in a particular module they are more likely to feel confident to access the centrally offered services outside of the formal teaching sessions.

If maths or stats clinics are not already offered centrally it may be useful to have discussions with staff in the central service. The key is not that these additional clinics are held only for one subject group but that students feel that those staffing the clinic understand the requirements of their module. A further advantage of having an interdisciplinary clinic is that the high and low demand of any particular group of students is spread across students where this is related to varying assessment deadlines. This helps to provide sufficient demand for the service throughout the teaching session.

It is important to discuss and recognise the terms of reference for support staff. If support staff feel pushed to engage in activities that they do not see as part of their role they may disengage. You also need to ensure that support staff receive a full set of materials for your module if they are to effectively support your students.

There may be the option of students arranging one-to-one appointments with a central advisor. Again, it is important to clarify the terms of reference and explain to your students what they can expect.

Another possibility, noted earlier, is to also engage higher year students as mentors. This provides an additional layer of support to students and the relative informality may encourage those students reluctant to use a central service to at least receive support from a peer. If the mentor themselves has experience of the central service, this may also help break down any barriers amongst more reluctant students.

\subsection{Assessment}

The forms of assessment in maths and stats need careful thought in order to maintain engagement throughout the teaching sessions. A number of options are outlined below. In many cases these may be combined:

1. Exam: The design of an exam can be used to test all the key maths or stats techniques. At the first year level it may be worth being transparent about the technique tested in each exam question. The reason for this is that students often do not appreciate that they need to have an understanding of the whole syllabus. In other words they can often enter the exam hoping that a particular technique will not be tested. Typically weaker students that only attempt a sub-set of exam 
questions struggle to reach a pass grade. However there must be consideration of assessing students to ensure that you do not find that a large number of able students all achieve close to $100 \%$. One approach may be to have the final part of each question more challenging. You may wish to be transparent about this so that weaker students are aware that they should move on rather than dwell on more difficult parts of questions.

Another consideration is whether you wish to have an open-book exam. This may be useful so that students are discouraged from memorising particular formulas or every step in a process and focus more on understanding the techniques relevant to particular problem and how the analysis should be interpreted. You should reflect on the learning outcomes for the module when weighing whether an open/closed book exam is more appropriate.

2. Phase-tests: The use of a number of small tests can be useful formative and summative assessment methods and, given their regular sequencing through the term, they can help to keep students focused on learning. There may be rules around the conduct of such tests at your particular institution; for example there may be a maximum student/staff ratio per room. Alternatively there may be a need to establish subject level principles if university rules do not exist. The number of phase tests may be determined by the number of weeks for which the module runs as well as whether you take a paper based or electronic testing approach. There can also be use of electronic testing outside the classroom where students have a designated time slot to take the tests. If tests are taken outside the classroom there are normally a greater number.

There may be reluctance to phase-tests due to the marking burden if these are paper-based. Therefore there needs to be some thought as to what is reasonable. For example, marking homework every week for a cohort beyond even 30 or so students may be difficult in terms of workload. There is a balance between ensuring continuous student engagement, particularly important for weaker students, and feedback as well as the marking workload of staff. As noted above, online resources may provide a more efficient means of providing regular feedback to students in addition to class exercises, rather than using assessed homework.

3. Group work: You may want to consider group assessment where students are asked to prepare a video explaining a key concept or why a concept is important when studying economics. Alternatively, you could ask students to produce a Powerpoint presentation and record an accompanying commentary (using the facility within Powerpoint). Once you check submissions for inaccuracies you could post selected submissions on your Virtual Learning Environment (VLE). The posted submissions may help other students with revision for a final exam as well as adding a competition element to the assessment task. 
There needs to be considerable thought as to how the groups for this task are constructed. For example, the groups could comprise of a range of students with different abilities to ensure a degree of mentoring. However there would need to be a degree of peer assessment to encourage a fair workload across group members. It is worth noting that an exercise of this type will need a reasonable level of IT and presentation skills, and this may be are area where students less able in maths are able to offer a greater contribution.

\section{Delivering economics modules relying on maths and stats skills}

\subsection{The balance of maths and stats content in economics lectures}

A successful strategy for engaging students in maths and stats for the study of economics requires a programme of well-considered modules with clear linkages between modules. Nevertheless it is often harder than it may seem. In part this is due to staff taking ownership of their module with less of a focus on the programme and students' learning as a whole. A second issue is that staff have different teaching styles and approaches. Therefore it needs a strong programme team and regular forums, such as team meetings and away-days, to resolve these potential issues.

\subsection{Planning seminar/workshop sessions}

Seminar/workshop sessions for core economics modules may be organised with a balance of questions around applied maths and stats alongside discussion questions or short presentations. This allows students to be reminded of maths and stats techniques, covered in the stand-alone maths and stats modules, whilst seeing their application. The key principle is that a solid understanding of economic principles is achieved when students can explain a concept using mathematical representation, graphical representation; where they can interpret relevant statistics alongside the ability to explain the concept in words, orally or in writing. Core economic module seminars/tutorials should bring together all of these approaches when asking students to explain key concepts. Discussing how errors in understanding can be realised and resolved through examining key concepts in different ways should encourage students of the appeal of this approach.

\subsection{Assessment}

The assessment of core economics modules should aim to test a student's ability to explain a concept using mathematical representation, graphical representation; the interpretation of relevant statistics as well as in explaining a concept in words. Core economics modules often include an exam as either part or the whole assessment of the module. There could be thought given to a compulsory question 
requiring students to present an answer that illustrates their ability to apply their maths and stats skills. This could be followed by a selection of essay style questions.

Another option could involve setting a report type of assessment allows a range of skills to be tested. It is important to give learners with different strengths an opportunity to illustrate their knowledge and understanding. In order to achieve this the teaching sessions leading up to the report submission should be tailored to develop the skills of a diverse cohort step-by-step. Group work can be helpful when carrying out the class tasks as different group members will have varying abilities to complete different tasks. There may be some thought as to the merits of a group report depending on the learning outcomes and range of student ability.

\section{Questions and Answers}

\subsection{What can I do if I am teaching a first year maths module with a high failure rate?}

\section{Step 1: Maths admissions criteria}

Obtain data on the performance and maths qualifications on admission of previous students taking the module. Assess these data to identify if there are any grounds for uplifting the maths entry requirement - are you setting students up to fail? The entry requirement will differ by institution depending on the varying demands of economics programmes.

\section{Step 2: Test/screen students during introductory/first week}

Design a test with the help of various internal and external support bodies. An example test is provided at the end of this chapter (section 7.1). The turn-around time will be tight so ensure that the test is reasonably quick to mark and that staff are on hand to undertake the marking.

\section{Step 3: Preliminary maths module}

Based on the test results decide on which students should be exempted from a preliminary maths module. An example preliminary maths module syllabus is provided at the end of this chapter (section 7.2). A second module attended by all students should follow this preliminary module.

\section{Step 4: Maths module organisation}

The seminars/workshops for the maths module that all students attend (following the preliminary maths module) should be organised according to the maths screening results in step 2 . 
Step 5: Checking the effectiveness of your strategy

Assess the results of the students and amend your strategy and screening tests as appropriate.

\subsection{Students are passing the $1^{\text {st }}$ year maths module but the staff teaching $2^{\text {nd }}$ year microeconomics and macroeconomics are concerned that students are not familiar with key maths/stats concepts. What should I do?}

\section{Step 1: Check your syllabus}

Check whether your syllabus provides suitable coverage of key techniques that are used in the microeconomics and macroeconomics modules. This will probably mean that you need to sit down with the leaders of the microeconomics and macroeconomics modules.

Step 2: Are you connecting the concepts in the maths/stats module with their economics application?

Once you have checked your syllabus you need to ensure that you are using economics examples that allow students to relate the maths/stats techniques to the content of the microeconomics and macroeconomics modules.

Step 3: Is your teaching and assessment strategy designed to ensure that the key concepts are embedded?

It may be that you need to consider more innovative ways to deliver the material depending on your group of learners. Your assessment strategy is also important as one final exam may lead to students disengaging and 'cramming' for the exam, rather than having a deeper learning and thus embedding concepts.

\subsection{I am teaching a maths/stats module and running lectures and seminars/workshops but attendance is very low. What should I do?}

\section{Step 1: Reconsider your syllabus}

It may be that students do not see the importance of the material covered in the module and are therefore disengaging. Reflect on how the material covered can be altered and linked to other modules in their programme of study.

\section{Step 2: Are you teaching sessions that provide an active learning experience?}

Students often disengage from a module if they do not feel that they are learning anything important. Therefore in addition to reviewing your syllabus you could look at whether the delivery of the module needs re-thinking. Perhaps you need to link the sessions more clearly to your assessment strategy for the module. 


\section{Step 3: Have you designed your assessment to encourage continuous participation in the module?}

If you have a one form of assessment it may be worth revising your assessment strategy to encourage continuous engagement throughout the teaching weeks. Consider using phase tests (see 2.6.2 above).

\section{Step 4: Are you following up non-attendance?}

It is worth checking what attendance monitoring takes place in your subject group. If non-attendance is not followed up frequently or at all it may be worth discussing if you can do so at the module level.

\subsection{I am teaching a maths/stats module and the weak students are no longer attending the sessions. What should I do?}

\section{Step 1: Have you streamed students according to ability?}

If you have not tested and streamed your students according to ability it is worth trialling this approach. It could be that the weaker students are reluctant to attend and attempt the tasks or ask questions for fear of looking 'stupid' and so they disengage.

\section{Step 2: Are you providing learning material that is accessible to your weaker students?}

It may be useful to reflect on whether the material provides a sensible starting point for weaker students. If you are concerned that you are going to end up teaching to the lowest ability students then why not think about longer sessions just for the weaker students? (see section 2.2 above)

\section{Step 3: Are you providing support outside the scheduled sessions for weaker students?}

You may wish to investigate some of the following: putting students into study groups; running maths clinics; a student-mentoring scheme.

\section{Top Tips}

1. Think carefully about the role of lectures in your modules delivery. Is a weekly lecture series really needed, or could you offer occasional lectures as signposting for learners with more workshop activity? Alternatively, are lectures required at all?

2. Consider streaming students according to ability, whilst carefully explaining the reasons to your students. 
3. Design innovative teaching sessions that maintain student interest, and forms of assessment that requires continuous engagement. Consider the use of in-class online quiz software, video clips and assessment of a video presentation.

4. Avoid focus on delivering to students with the lowest ability. Stretch your higher ability students whilst supporting weaker students. You could provide extra supported learning time for weaker students, whilst tasking stronger students to use software to visualise maths or stats techniques.

5. Engage support staff and student mentors. Find out the help available outside your department to support your maths/stats students. Also consider engaging students in the later stages of their degree to act as student mentors.

6. Ask students for their views of their learning experience formally and informally throughout the teaching weeks. Provide feedback on how you have responded to their comments i.e. 'make it count'.

\section{Research}

Alauddin, M. and Butler, J.E. (2004) "Teaching Economics in a Changing University Environment: Some Australian Experience",International Journal of Social Economics, Vol. 31, No.7, pp.706-720. DOI: $\underline{10.1108 / 03068290410540891}$

Dancer, D.M. and Fiebig, D.G. (2004) "Modelling Students at Risk", Australian Economic Papers, Vol. 43, No. 2, pp. 158-173. DOI: 10.1111/j.1467$\underline{8454.2004 .00222 . \mathrm{x}}$

Dunn, R., Griggs, S.A., Olson, J., Beasley, M. and Gorman, B.S. (1995) “A MetaAnalytic Variation of the Dunn and Dunn Model of Learning-Style Preferences", The Journal of Educational Research, Vol. 88, No. 6, pp. 353362. DOI: $10.3200 / J O E R \cdot 101.2 .94-98$

Entwistle, N. (1981) Styles of Learning and Teaching; an integrated outline of educational psychology for students, teachers and lecturers Chichester: John Wiley.

Honey, P. and Mumford, A. (1982) Manual of Learning Styles London: P Honey.

Leung, F.K.S. (2001) "In Search of an East Asian Identity in Maths Education", Educational Studies in Mathematics, Vol. 47, No. 1, pp. 3551. DOI: 10.1023/A:1017936429620

\section{Internet Resources:}

The Economics Network http://www.economicsnetwork.ac.uk/ 
Mathematics for Economics: enhancing Teaching and Learning (METAL) http://www.metalproject.co.uk/

Statistical Resources for Social Sciences (DeSTRESS)

http://www.economicsnetwork.ac.uk/statistics

\section{Resources}

\subsection{Case Study 1: Maths diagnostic test}

At several points it has been suggested that an initial screening test can be extremely helpful in identifying students who need more support, either in a dedicated module or in longer workshops. The following maths diagnostic test has been developed at the University of Bradford. This test is included within this chapter as it may provide useful guidance to staff in other institutions considering introducing maths screening. A similar approach could be taken in relation to statistics.

Please note that the University of Bradford has a minimum entry requirement of GCSE grade C in maths. The pass threshold currently used is $70 \%$. All students below this are required to take the first semester preliminary maths module.

A note of caution: this test format may not be appropriate in a different institutional context even if the maths entry requirement is identical. You should reflect on the appropriateness of any test based on the skills required of your students given the demands of your programme.

- Download test in Microsoft Word format

\subsection{Case Study 2: Preliminary maths module}

Following the maths diagnostic test students may be selected to attend a preliminary maths module. The syllabus and assessment schedule adopted at the University of Bradford is listed below. A few points to note:

1. This material is foundation level so if a similar module were put on at another institution there would need to be a facility for students taking credits out of stage/year.

2. The level of the material of the module indicated below is such that there needs to be serious consideration of appropriate staffing. School/college maths teachers are ideal for delivery at this level.

3. The module below does not have a 'big' final exam. Instead, the assessment is reasonably evenly spread over the teaching weeks to ensure continuous engagement. Note that ensuring engagement is very important for weaker ability students who often find material 'hard' and 'boring'. Nevertheless 
there is significant staff marking burden as well as the organisation of the test slots.

4. There needs to be clear accompanying material for students, such as practice booklets. It is important that students are encouraged to keep their practice booklets, with their own notes, for future reference.

\begin{tabular}{|c|c|c|}
\hline \multicolumn{3}{|c|}{ Weekly Plan } \\
\hline Week & Topics & Assessment \\
\hline 2 & $\begin{array}{l}\text { Number: } \\
\text { Order of calculation } \\
\text { Negative numbers } \\
\text { Fractions }\end{array}$ & \\
\hline 3 & $\begin{array}{l}\text { Decimals } \\
\text { Percentages \& interest }\end{array}$ & \\
\hline 4 & $\begin{array}{l}\text { Converting between fractions, decimals and } \\
\text { percentages } \\
\text { Decimal places \& sig figs (rounding) } \\
\text { Ratio }\end{array}$ & Test $-30 \%$ \\
\hline & Directed Study Week & \\
\hline 6 & $\begin{array}{l}\text { Introduction to Algebra: } \\
\text { Writing expressions } \\
\text { Solving linear equations } \\
\text { Simplifying expressions } \\
\text { Multiply out brackets }\end{array}$ & \\
\hline 7 & $\begin{array}{l}\text { Powers \& roots } \\
\text { Financial maths }\end{array}$ & \\
\hline 8 & $\begin{array}{l}\text { More Algebra: } \\
\text { Linear factorisation } \\
\text { Function Notation } \\
\text { Formula substitution } \\
\text { Re-arranging expressions }\end{array}$ & \\
\hline 9 & $\begin{array}{l}\text { Multiply out } 2 \text { brackets } \\
\text { Quadratic equations: } \\
\text { Solve by formula } \\
\text { Discuss factorisation (for easier ones) if time. }\end{array}$ & Test $-30 \%$ \\
\hline 10 & $\begin{array}{l}\text { Geometry: } \\
\text { Straight line graphs: sketching by finding } \\
\text { intercepts }\end{array}$ & \\
\hline 11 & Sketching curves & \\
\hline 12 & Revision & Final Test $-40 \%$ \\
\hline
\end{tabular}


http://www.economicsnetwork.ac.uk/handbook/maths_stats 